\title{
Creatividad léxica y tratamiento lexicográfico: El caso de Vargas Llosa y La casa verde
}

\author{
CARLOS ARRIZABALAGA \\ Universitat de Piura (Perú)
}

En la lexicografía regional peruana ocupa un lugar destacado el aporte del embajador Juan Álvarez Vita, representante diplomático del Perú ante países como Cuba e Indonesia y estudioso de los derechos humanos y las relaciones internacionales. Gracias a su experiencia y su interés por las regiones del país, así como por sus lecturas y sus conocimientos literarios, logró reunir, siguiendo de modo más o menos intuitivo el método de la «tradición diferencial» (Carriscondo 2006: 699) un extenso Diccionario de peruanismos, que se publicó por primera vez en 1990 y se acaba de reeditar, corregido y ampliado, el año 2009. Sin duda es un caso de especial significado por la abundancia de los términos y acepciones registradas, si bien se trata de un lexicógrafo diletante cuya fortuna proviene de su acuciosidad y constancia más que por la aplicación de métodos y conceptos rigurosamente lexicográficos (Ahumada 2003: 61; Carriscondo 2003: 343).

Luis Jaime Cisneros reconocía el gran valor de la obra del embajador Álvarez Vita, quien por lo general se muestra cauto en sus interpretaciones. Aurelio Miró Quesada y Marco Martos también han elogiado el enorme esfuerzo recopilatorio del diplomático. El propio embajador me señalaba en una ocasión que muy pocas han sido las ocasiones en que le han hecho ver alguna falla o inconsistencia en su repertorio que, pese a no ser la obra de un especialista, tiene la virtud de reflejar una muy buena parte - si no todo- del léxico peruano actual que marca una diferencia con el español general, aunque incluye términos compartidos con otras naciones de Hispanoamérica. Generalmente también trata de precisar la extensión de las significaciones, cuando se restringen a alguna región geográfica del país. En realidad, en su encomiable esfuerzo parece estar empeñado en acopiar el mayor número de términos y para ello se apoya directamente en su conocimiento de las variedades del español peruano y en muy diversas fuentes literarias.

Una golondrina no hace verano, pero no deja de ser sintomático. Vamos a considerar solamente dos palabras recogidas por error en el repertorio de Álvarez Vita; dos entradas referidas a palabras que no han sido consideradas adecuadamente debido al exceso de confianza otorgado a la autoridad del conocido escritor Mario Vargas Llosa. Ambas se refieren a un origen supuestamente norperuano:

(1) atropellada. (Piura). Mujer que ha sido sexualmente violada. (1990: 68).

(2) fusiliquito. (Costa Septentrional). Persona nacida como consecuencia de una violación (1990: 251). 
Como Piura es la provincia mayor dentro de la costa norte peruana, se entiende que las referencias geográficas se vuelven casi equivalentes, con la salvedad de que en el segundo caso podría abarcar también, presuntamente, las provincias limítrofes de Tumbes y Lambayeque. Sin embargo, el hecho es que esos términos no se emplean en esa región y por supuesto no figuran en ningún diccionario de localismos norteño.

No se trata de palabras «fantasma» en sentido estricto. Álvarez de Miranda (2000) encontró palabras y acepciones fantasma en los diccionarios de la Academia que se habían incorporado fundamentalmente por confusión, como cuatratuo, que fue una mala lectura de cuadralbo [quatralvo], pero salió así impresa, en Lisboa, en la Florida del Inca Garcilaso. El caso de Álvarez Vita es diferente, pues esos términos los lee correctamente de la fuente original, sin percatarse de que da como fidedigno un testimonio que es ficcional. Particularmente el norte del Perú cuenta con una abundante colección de repertorios lexicográficos, desde la temprana incursión de Martha Hildebrandt (1949). Se trata de una lexicografía regional de carácter diferencial hecha en su mayoría por aficionados, repertorios y glosarios de carácter lexicográfico, algunos referidos solamente a pequeñas localidades dentro de la provincia. Me refiero a los diccionarios de Edmundo Arámbulo Palacios (1995) y de la miscelánea de Carlos Arellano (1996), además del diccionario de folclore recopilado por Esteban Puig (1985 y 1996), entre otros.

\section{UN JUEGO DE APARIENCIAS}

Álvarez Vita conoce muy bien la obra de Vargas Llosa, y detecta estas palabras en un breve pasaje de La casa verde (1966), cuya acción transcurre en dos rincones de la selva norperuana, en contacto con los idiomas de los pueblos aguarunas y huambisas, y en la ciudad de Piura, efectivamente, en la calurosa costa del extremo norte peruano, un espacio caracterizado a su vez por un dialecto castellano peculiar (Arrizabalaga 2012b).

Muchos escritores han hecho gala de su atención hacia las hablas populares y no faltan en Piura los narradores que han reflejado con más o menos acierto el vocabulario regional. Enrique López Albújar (1872-1966) incluso añadió un glosario a alguna de sus obras. Francisco Vegas Seminario (1899-1988) resaltaba en negrita los regionalismos de sus novelas. Vargas Llosa también refleja como es natural las peculiaridades léxicas peruanas, pero está muy lejos de ser un intérprete fidedigno de las hablas locales y aborrece de ese afán tan telúricamente latinoamericano de trasladar a la literatura torrentes de palabras exóticas. Pese a la impresión inicial que se refleja en algunos estudios tempranos, los peruanismos que emplea en sus novelas son más bien escasos y definidos. En realidad, aplica un bisturí para extraer del léxico real tan sólo algunos términos y algunas maneras de hablar que dan un ligero color local a la narración sin impedir que ésta deje de ser comprensible desde otros ámbitos, con una dimensión más universal ${ }^{1}$.

${ }^{1}$ Sobre el lenguaje y el estilo de Vargas Llosa, véase Martín (1974). Sobre el léxico de la novela, véase Alonso (1972: 11-20), Álvarez García (1992), Enguita (2002) y también Arrizabalaga (2012a). 
El procedimiento usual en la narrativa anterior era más simple pero a la vez el más evidente de la equivalencia lexicográfica, empleando con frecuencia términos equivalentes como definición. Por ejemplo, López Albújar, recordaba los odiosos castigos que empleaba aquel profesor que les «hacía hincar sobre saquetes de checos o boliches a los que sorprendía jugando con estos objetos» (1924: 139). No pocos autores, como el autor de Matalaché, incluían glosarios para facilitar la lectura. La renovación de la narrativa latinoamericana, decía Carpentier, acabó también con «los tiempos de las novelas con glosarios adicionales» (cit. Oviedo 1984: 460).

En verdad Vargas Llosa resuelve de formas muy variadas y con verdadera maestría, el problema del lenguaje, aprovechando la capacidad caracterizadora de las palabras y su enorme poder simbólico como signos del espacio en que se habita pero sin caer en el folclorismo torpe que justifica en el regionalismo sus descuidos. Al contrario logra darle al localismo una funcionalidad narrativa. Vargas Llosa trata de que las palabras netamente piuranas no distraigan la atención del lector: aparecen las más de las veces incorporadas al texto sin más explicación que la que se logra por el contexto: «los cascarones y los globos llovían sobre enfurecidos transeúntes» (1966: 108). Los explica con sutiles equivalencias entre el término local y el general: «salió jalando el piajeno cargado de ropa sucia [...] el asno enderezó las orejas, rebuznó» (1966: 161). O se definen al revés: «el asno, ese piajeno de pelaje amarillento y andares lentos y rumbosos» (1966: 182). Y son más frecuentes en los diálogos:

Nada de chifas - dijo Lituma-. Quiero platos piuranos. Un buen seco de chabelo, un piqueo, y clarito a mares. (1966: 40)

En un brevísimo fragmento de la novela, sin embargo, parecería a primera vista que el escritor hace una concesión excepcional a ese «folclorismo» que tanto aborrecía y que trataba por todos los medios de superar. Es un momento en que hace referencia al modo como soldados borrachos forzaban en grupo a las pobres mujeres que trabajaban lavando ropa y a las empleadas que iban al mercado, por el barrio de Buenos Aires. La violación colectiva o grupal se muestra como parte de la vida cotidiana y para acentuar la impresión de habitualidad finge una suerte de valor idiomático local a sus respectivas denominaciones:

Los piuranos llaman atropellada a la víctima, y a la operación fusilico, y al vástago resultante lo llaman hijo de atropellada, fusiliquito, siete leches. (1966: 140)

Vargas Llosa, que está en las antípodas de cualquier interés localista, se presenta de repente y como nunca hecho un narrador lexicógrafo que interrumpe con todo un vocabulario del estupro, dando la apariencia de que los piuranos emplean con naturalidad toda una suerte de vocablos como para dar la impresión de que tales atrocidades caracterizaban la ciudad y eran pan de cada día ${ }^{2}$. Los soldados ebrios lo hacían tan a menu-

\footnotetext{
${ }^{2}$ Los apuntes lexicográficos no eran raros en la literatura anterior y particularmente en la generación española del 98. Dirá Unamuno: «En Fuerteventura se llama güelfo al camello mamón o de leche, luego majalulo, hasta que empieza a trabajar, a los tres años, y luego camello» (1981: 56). Véanse más ejemplos en García Gallarín (1998: 107-112).
} 
do, dice Vargas Llosa, que esa zona cercana al cuartel se llamaba también supuestamente «matorral de los fusilicos».

Es difícil establecer los límites entre la realidad y la ficción, pero este extremo es fantasía. En la novela no faltan vocablos inventados por el propio Vargas Llosa, como los de «habitanta» e «inconquistable» que se reiteran hasta el cansancio en La Casa Verde, pero resultan en realidad desconocidos en el habla piurana (y claro está que no se registran tampoco en ningún diccionario). Lo decía, hablando de la novela en general, José Miguel Oviedo:

En todos sus niveles - real, simbólico, conceptual, formal- La Casa Verde es una novela que convierte la lectura en un acto de creación y que exige un sujeto atento, activo y sensible a los variables registros y texturas que el libro le propone (1970: $163)$.

Por el barrio de Buenos Aires, en la Piura de los años 40, había sí barrancos entre secos arenales y en la esquina de lo que luego será la avenida Loreto estaba la bodega donde doña Chepa vendía licores. Más allá se extendía el desierto y un barranco que en los años lluviosos abrazaba a la ciudad con un brazo de su caprichoso río. En efecto, en los barrancos suele haber matorrales (que en Piura se conocen como «chopes»), y atropellos infames han podido ocurrir en aquellos años en Piura como en cualquier otra ciudad del mundo ${ }^{3}$. Hasta lo que he podido indagar, luego de vivir muchos años en la ciudad, nunca hubo en Piura un matorral con nombre propio ${ }^{4}$.

El primer eufemismo (atropellada) es inventado, aunque siempre se le puede decir a la mujer que ha sufrido una violación y no faltan en la sociedad piurana eufemismos como ese atropello. En el campo de Piura se le dice en realidad sucedida (no lo recogen Puig ni Arámbulo pero lo explica Carlos Robles muy bien): la mujer joven que ha perdido la virginidad (distinción que revela un acendrado machismo en la región, aunque esto no viene ahora al caso). Ese diminutivo fusiliquito tampoco existe ni en Piura ni en ninguna parte del mundo aunque siempre sea posible su aparición efímera como ocurre en la creación literaria, igual que la expresión: «hijo de atropellada». Incluso cabe suponerle un significado, pero eso no basta para que tenga, como le gustaba decir a Ricardo Palma, «carta de ciudadanía».

Vargas Llosa vuelve a emplear la referencia en su drama La Chunga (1972), en lo que resulta evidentemente un remake de la novela:

La casa de la Chunga está detrás del Estadio poco antes del descampado que separa a la ciudad del Cuartel Grau, no lejos del matorral de los fusilicos. Allí, en ese paraje de yerba calcinada y tierra blanda los soldados ebrios tumban a las lavanteras o las criadas, unos tras otros (1972: 140).

\footnotetext{
${ }^{3}$ El abuelo del escritor, don Pedro Llosa Bustamante, pariente cercano del presidente Bustamante y Rivero, ejercía la función de Prefecto de la provincia en 1946, cuando Vargas Llosa cursó estudios de quinto de primaria en Piura, y pudo haber tomado noticias o rumores acerca de estupros o agresiones ocurridas en aquel año o con anterioridad, pero no hay constancia de ello.

(1971: 12).

${ }^{4}$ Vargas Llosa describirá luego Piura como una ciudad rodeada de arenales y ralos algarrobos
} 
En la traducción inglesa de la novela, a cargo de Gregory Rebassa, no se mantienen los mismos términos pero se buscan expresiones eufemísticas que tengan cierta equivalencia, salvo en el último caso que se traduce literalmente aunque no resulte en una expresión idiomática y su interpretación sea precaria:

Piurans call the victim a knockdown, the operation gunning, and the resulting heir is called son of a knockdown, son of a gun, seven-creamer (Vargas Llosa 2005 125)

El último término nos permite confirmar que esta es la fuente de Álvarez Vita porque también otorga a «sieteleches» el significado que se le atribuye en ese pasaje y no el que tiene en realidad (y el que se manifiesta en otros pasajes de la novela). Son dos palabras fantasma y una acepción forzada que no se emplean en Piura y no figuran en ningún otro diccionario, y es que en realidad no deberían estar en ninguno. El engaño es una muestra de la gran habilidad que tiene Vargas Llosa para crear una obra de ficción empleando para ello elementos de la realidad de una manera aparentemente objetiva y rigurosa. Puesto que existen en el Perú y otros países de América los términos fusilico y sieteleches, palabras hoy en desuso y tradicionalmente consideradas groseras, pese a haber surgido como flagrantes eufemismos: el peso de la dolorosa realidad se impone.

\section{PALABRAS DE LA REALIDAD}

Mario Vargas Llosa vivió en la pequeña ciudad provinciana de Piura dos breves periodos: los años 1946 y 1952 en que cursó, respectivamente, el quinto año de primaria en el Salesiano y quinto de secundaria en el Colegio San Miguel. Este último sobre todo le produjo un entusiasmo intelectual y vital que siempre recordará con nostalgia, y Piura se convertirá en escenario literario del boom casi tanto como Macondo o Comala, con la diferencia de que sus calles y vecinos existen en verdad y no solo en las páginas de La casa verde, Los jefes o ¿Quién mató a Palomino Molero?

Vargas Llosa emplea con naturalidad no pocos vocablos del habla popular norteña, que trasmiten una atmósfera muy peculiar: churre, piajeno, seco de chabelo, chifles, natillas, algarrobina, y así caracteriza además a sus personajes, como don Anselmo, que pronto aprendió a decir «gua» para mostrar asombro, hasta hacerse «mangache». Albert Bensoussan (2007) confiesa por ello que para traducir al francés las obras del premio Nobel le fue especialmente útil el diccionario de Esteban Puig ${ }^{5}$. Vargas Llosa trata de superar la novela telúrica anterior, aun asumiendo sus temas y escenarios, y consigue que también los americanismos léxicos se expliquen por sí mismos y tengan verdadera autonomía dentro de la novela ${ }^{6}$.

\footnotetext{
${ }^{5}$ Véase Arrizabalaga (2012: 149-151)
}

${ }^{6}$ Miguel Delibes apreciaba el uso que hacía Vargas Llosa del lenguaje popular peruano «tan hermoso», mientras que Caballero Bonald advertía que su narrativa no era un "costumbrismo universalizado» sino una «transposición épica de unas determinadas realidades sociales» (cit. Tola de Habich y Grieve 1971: 56 y 129). 
Pese al realismo de su prosa no todo es real, ni mucho menos, ni tampoco el lenguaje. Algunas palabras fueron acaso fugazmente escuchadas en las aulas o incluso imaginadas por el jovencito estudiante de secundaria, como la metáfora infantil y cucufata de habitanta que da a las prostitutas de La casa verde y el apodo de eterno adolescente de inconquistables que se arrogan Lituma y los suyos. Se reiteran hasta el cansancio y por toda la ciudad en La Casa Verde, pero son desconocidos en la realidad del habla piurana de hoy como entonces ${ }^{7}$.

Fusilico es una metáfora diríamos «gruesa», hoy en desuso, tomada del nombre americano de un juego de naipes antiguo en que la carta pasaba de mano en mano. Todavía lo recoge con ese sentido el jesuita Ruben Vargas Ugarte (s.f.: 21) y en el siglo XIX lo trae el diccionario bilingüe de Mariano Velázquez (1858: 222), así como los centroamericanos Membreño (1982:89) y Cagini (1919: 142). El primero explica perfectamente las características generales del fusilico:

Cierto juego de naipes que se juega entre cuatro personas, si es tapado, o entre dos si es destapado. En este juego las cartas tienen el mismo valor que en el del trueque (Membreño 1982: 89).

El costarricense añade un detalle:

En el juego de fusilico dar mantilla es dejar a los contrarios apenas con una o dos pintas (tres pintas o figuras se cuentan por un punto (Cagini 1919: 175).

Neves consignaba el término como propio de Centroamérica. El Diccionario de americanismos recoge ahora como propia de Honduras y Nicaragua la acepción de fusilico como juego de cartas y como peruanismo la de «agresión sexual colectiva cometida contra una mujer» (2010: 1014).

Rubén Darío recuerda que cuando era niño venían a su casa el cura y el platero «a jugar fusilico» con su madre y su tía (1968: 20) ${ }^{8}$. En el Perú, el clérigo Larriva imaginaba hacia 1828 jugando fusilico, en una vespertina reunión limeña, a los personajes que ponen al libertador Bolívar «como ropa de Pascua», al decir de Ricardo Palma,

en casa de ciertas jóvenes en que se reúnen varias gentes de humor a pasar el rato con una partida de rocambor y otra de fusilico (1864: 129).

A mediados del siglo XX se aplicó, al parecer en el Perú solamente, a la agresión sexual colectiva ${ }^{9}$. Guillermo E. Bendezú Neyra, lo considera vocabulario del hampa, entre los términos que «ya circulan con notable fluidez en el habla popular» en las calles de Lima (1975: 26) ${ }^{10}$. También lo registra Francisco Izquierdo Ríos (1975: 139). El narrador neorrealista Enrique Congrains Martín (1932-2009) lo emplea en una esce-

\footnotetext{
${ }^{7}$ Véase la explicación que ofrece el propio escritor al término de habitanta como eufemismo infantil (1971: 14).

${ }^{8}$ En esta edición de la Autobiografia del poeta nicaragüense escriben por error fusílico en lugar de fusilico.

${ }^{9}$ En Panamá se dice de la persona inquieta y agitada (Isaza 1968: 59)

${ }^{10}$ Luego lo incluye en su repertorio de la jerga criolla, con el ejemplo: «estuvo comprometido en el fusilico de la negra Maruja...» (1977: 169).
} 
na realmente cruda de su novela No una sino muchas muertes, que también está ambientada en Lima:

A los muchachos ya les está picando el cuerpo, tenemos que hacer un poco de fusilico. Nada de patalear, nada de arañar o de morder, es mejor que te portes bien con nosotros esta noche $(1975: 126)^{11}$.

En total se emplea nueve veces el término fusilico en la novela de Congrains, que está ambientada totalmente en Lima en los años 60, los que conoció el joven periodista Vargas Llosa. De hecho, en La casa verde se emplea fusilico en una ocasión y no con el significado que le atribuía supuestamente a los piuranos, sino como sinónimo de cualquier tipo de agresión grupal tal como se empleaba en Lima en aquellos años:

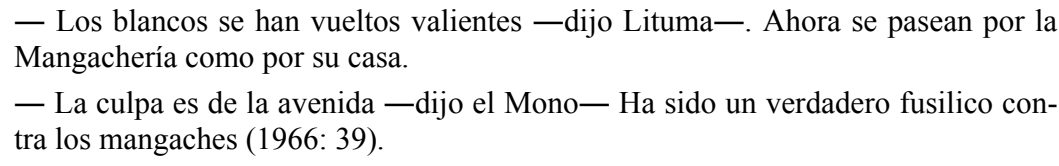

Sieteleches, en cambio, es americanismo que tuvo cierta vitalidad un tiempo en Perú, Bolivia, y otras zonas de Sudamérica, especialmente Argentina y Venezuela, pero que ya se encuentra en desuso, propio de personas ancianas. En Piura ya no se emplea. Lituma se lo dice a la selvática entre otros insultos ferozmente sinónimos: «puta, arrastrada, siete leches», para acabar sollozando en la arena «como un churre» (1966: 190). Ludovico le dice a Calancha «hijo de siete leches», en Conversación en La Catedral (1969: 243), y es el mismo insulto que aplica Pedro Livio Cedeño a su torturador en $L a$ fiesta del chivo, espetándole que su madre fue «de burdel antes de ser la querida de Trujillo» (2000: 436). En fin, fue el insulto que el jesuita Francisco Iturri, natural de Santa Fe del Paraná, empleó contra el historiador oficial español don Juan Bautista Muñoz a fines del siglo XVIII (1798: 230).

Es un insulto que no tiene el significado estricto de 'fruto de la violación sexual', sino funcionaba como sinónimo de bastardo, hijo de cualquiera, hijo no reconocido o de padre no conocido. Como cualquier insulto, su carga despectiva borra o desfigura el posible contenido referencial del significado originario, puesto que la función representativa queda anulada por imposición de la función apelativa.

Un personaje de Ignacio Aldecoa nos muestra que en el campo español se conocía una expresión similar: el insulto "hijo de cien leches», con similar fuerza despectiva (1954: 176). La frase se habría formado pues en el fecundo siglo XVIII porque todavía en 1646, el anónimo autor del Estebanillo González reclama la malicia de algunas que tienen «hijos y nietos de diferentes padres, como quesos de muchas leches» (1646 (1990): II, 278), y se advierte aún el sentido literal de la frase, que juega a dos bandas pues «hijo de leche» significaba, en español clásico, el criado por la nodriza. De ahí decir que son siete o cien es convención idiomática y no depende más que la cabalística de la hipérbole y de la eufonía de las cifras.

\footnotetext{
${ }^{11}$ Ver otros ejemplos en Congrains (1975: 128 y 132).
} 
Piura es una tierra fértil en eufemismos: piajeno por burro, cascarones por huevos, oriento por idiota, ñisca o ñoña por excremento; pero fusilico y sieteleches, que pueden considerarse de alguna manera eufemismos que se tornan groseros, nunca han sido expresiones peculiares piuranas, y finalmente, las palabras atropellada y fusiliquito ni siquiera existieron en el vocabulario.

Todo parece tomado de un mal chiste fugaz sacado de las no tan pudorosas aulas sanmiguelinas o de una noche de parranda entre reporteros, con Carlos Ney y otros que conoció el escritor siendo todavía muy joven en La Crónica o en La Industria (Gargurevich 1985), que en aquellos años defienden el empleo de la jerga o repasan el lenguaje del hampa..., eso sin que falte ni pueda menospreciarse la maestría del juego estilístico — tremendamente hábil por cierto- del escritor.

Quiero decir que Vargas Llosa utiliza un tópico usual del costumbrismo y de la narrativa telúrica anterior pero no para tratar de refrendar la ficción con datos obtenidos de la realidad sino para hacerla más verosímil con datos que son sin embargo ficticios.

\section{INTERPRETACIONES CRÍTICAS}

El escritor mejicano, recientemente fallecido, Carlos Fuentes reflexionaba al cabo de la novela sobre la identidad latinoamericana, y espetaba con desenfado que los españoles habían llenado América de fusiloquitos (curioso cómo confunde el término como si viniera de loco). Es lo que llama «la bastardía fundadora» (1976: 45). Para él la conquista fue un enorme atropello, un fusilico descomunal. Con idéntico argumento ideológico explica Julio Roldán la peruanidad.

$$
\begin{aligned}
& \text { el atropello ha sido el origen de nuestra formación histórica, los mestizos o fusili- } \\
& \text { quitos el resultado, individuos que odian al padre biológico, pero a la vez quieren y } \\
& \text { buscan al padre histórico. Frecuentemente quieren a la madre de carne y hueso, } \\
& \text { despreciando a la madre histórica y todo lo que está relacionado con ello y su cul- } \\
& \text { tura; son la contradicción en persona (Roldán 2000: 105). }
\end{aligned}
$$

No es momento para argumentar en torno a la identidad latinoamericana. En la novela, a nuestro modo de ver, importan más los demonios del propio Vargas Llosa y su más que compleja relación con su propio padre. Sea como fuere, también el término fusiliquito es creación literaria, pero al emplearlo en sus reflexiones Fuentes y Roldán terminan por dar la razón finalmente al diccionario de Álvarez Vita, al dar empleo real a un término que sólo había existido en la imaginación del novelista.

No es que falten burdeles, lamentablemente, ni atropellos sexuales y de todo tipo en Piura como en cualquier otra parte del mundo, sino que no existen en ese dialecto del español americano las palabras con que se argumenta que Piura y toda América Latina es un atropello, tomando como caso ejemplar lo que es invención literaria que se apoya en una realidad personal más que en un hecho social. Seguramente el énfasis que adquiere el asunto en la novela es más reflejo traumático de una experiencia del autor e indicio de «la carencia nostálgica de una figura paterna positiva» (Boldori 1974: 34), y no tanto característica singular de una región ni menos aún marca original de la identi- 
dad latinoamericana ${ }^{12}$. Aunque efectivamente Latinoamérica presenta los índices más altos del mundo de hijos fruto de relaciones no oficializadas, es decir, de hijos fuera del matrimonio o fruto de relaciones de convivencia no formalizadas, y no son precisamente pocos los burdeles y los casos de abusos que se cometen en Piura ${ }^{13}$. Ahora bien, la generalización de lo particular produce una notoria distorsión de la realidad, pero se impone una determinada interpretación de la realidad latinoamericana y La casa verde se convierte en un símbolo de determinada comprensión ideológica (Oviedo 1984: 449).

La Piura de Vargas Llosa es una ciudad alucinada y el escritor emplea magníficamente el escamoteo de algunas palabras ficticias entre otras verdaderas atribuyendo al dialecto local toda una familia léxica del lenocinio con la que procura hacer más creíble la atmósfera atropellada de la novela. La «verdad real» es una cosa y la «verdad literaria» otra, y sacar la verdad de las mentiras exige la máxima prudencia a los intelectuales de entonces y de ahora. También nos obliga a prestar una mayor atención a los lingüistas, y especialmente a los escribidores de diccionarios, cuya labor merece siempre todos los elogios.

Para Vargas Llosa la creación literaria es un «proceso de desnaturalización de la realidad o reconstitución de una irrealidad en forma de realidad a través de la literatura» y por ello es «un testimonio falaz pero, al mismo tiempo, un testimonio profundamente instructivo» (1985: 66). De hecho, es capaz de suscitar importantes ensayos sobre la realidad latinoamericana.

\section{CONCLUSIÓN}

Vargas Llosa instrumentaliza magistralmente la variación dialectal. Utiliza un artilugio aparentemente documentalista para crear una apariencia de realidad en la novela, pero por supuesto no tiene ninguna intención lexicográfica. Pese a hallarse lejos de aceptar la idea de que la literatura deba ser quiera o no expresión de una especificidad regional, nacional o latinoamericana ni siquiera un reconocimiento de una mayor o menos heterogeneidad. Pero asentado que esta heterogeneidad existe en cualquier caso, no hay objeción para convertirla en parte de la ficción, inventando palabras o haciéndolas parecer hechos dialectales.

En conclusión, Vargas Llosa hace una parodia de las maneras y preocupaciones del discurso telúrico localista anterior y a la vez se aprovecha de esa tradición para dar verosimilitud a un elemento de ficción. Una parodia, por supuesto, no puede servir para autorizar un diccionario y el desliz del embajador Álvarez Vita al considerar que bastaba la autoridad del escritor no es que sea disculpable, pero en sí parece muy comprensible.

\footnotetext{
${ }^{12}$ Sobre los demonios de Vargas Llosa y la difícil relación que mantuvo con su padre, véase también Boland (2003: 20) y Silva Tuesta (2012: 45).

${ }^{13}$ En el Perú, las parejas que no formalizan su relación están en aumento. Datos del INEI permiten comprobar que la cohabitación o convivencia ha crecido sostenidamente desde el 2004 (19\%) hasta el 2010 $(22 \%)$.
} 


\section{REFERENCIAS BIBLIOGRÁFICAS}

AHUMADA, Ignacio (2003): «Tradición y actualidad en la lexicografía sobre los regionalismos en español: las fuentes escritas», en Lexicografia y lexicología en Europa y América: Homenaje a Günther Haensch en su 80 aniversario, Madrid, Gredos, pp. 61-75.

ALDECOA, Ignacio (1954): El fulgor y la sangre, Barcelona, Planeta.

Alonso, María Rosa (1972): Agresión a la realidad: Mario Vargas Llosa, Las Palmas, Inventarios Provisionales.

ÁlVAREZ DE MiRANDA, Pedro (2000): «Palabras y acepciones fantasma en los diccionarios académicos», en J.-C. Chevalier y M.-F. Delport, eds., La fabrique des mots. La néologie ibérique, París, Presses de l'Université de Paris-Sorbonne, pp. 55-73.

ÁlVAREZ GARCÍA, Manuel (1992) : «Indoamericanismos léxicos que designan animales en La Casa Verde de Mario Vargas Llosa», Cauce, 14-15, pp. 13-24.

Álvarez Vita, Juan (2009): Diccionario de peruanismos. El habla castellana del Perú, Lima, Universidad Alas Peruanas.

ANÓNIMO (1646 [1990]): La vida y hechos de Estebanillo González, edición de A. Carreira y J. A. Cid, Madrid, Cátedra.

Arámbulo Palacios, Edmundo (1995): Diccionario de piuranismos, Piura, Municipalidad Provincial de Piura.

Arellano Agurto, Carlos (1996): Piuranidades. Dichos y costumbres de Piura, Piura, Sietevientos.

ARRIZABALAGA, Carlos (2012a): «Piuranismos en La casa verde de Mario Vargas Llosa», en M. Martos y C. Arrizabalaga, eds., Actas del Congreso Internacional de Lexicología y Lexicografia Carlos Robles Rázuri, Lima, Academia Peruana de la Lengua y Universidad de Piura, pp. 25-56.

(2012b): El dejo piurano y otros estudios, Piura, Caramanduca.

ASOCiACIÓN DE ACADEMIAS DE LA LENGUA ESPAÑOla (2010): Diccionario de americanismos, Madrid, Santillana.

BENDEZÚ NeYRA, Guillermo E. (1975): Vocabulario hampesco, Lima-Ayacucho, Gráficas Popular.

(1977): Argot limeño o Jerga criolla del Perú, Lima, edición del autor.

Bensoussan, Albert. (2007): «Traducir a Vargas Llosa», en R. Boland y I. Enkvist, Una pasión por la literatura. Estudios críticos sobre Mario Vargas Llosa, Jannali (Australia), Antípodas Monographs, II, pp. 37-48.

Boland, Roy C. (2003): Una rara comedia. Visión y revisión de las novelas de Mario Vargas Llosa, New Mexico, Research University Press.

BolDORI, Rosa (1974): Vargas Llosa: un narrador y sus demonios, Buenos Aires, Fernando García Cambeiro.

CAGINI, Carlos (1919): Diccionario de costarriqueñismos, San José, Imprenta Nacional.

CARRISCONDO ESQUIVEL, Francisco (2003): «La lexicografía regional del español peninsular», Moenia, 9, pp. 339-358.

(2006): «La lexicografía del español de América», Bulletin of Spanish Studies, 83, pp. 695-709.

CONGRAINS MARTín, Enrique (1975): No una sino muchas muertes, Barcelona, Planeta.

DARío, Rubén (1968): Autobiografia, Buenos Aires, Eudeba.

FUENTES, Carlos (1976): La nueva novela hispanoamericana, México, Cuadernos de Joaquín Mortiz. 
Garcia Gallarín, Consuelo (1998): Léxico del 98, Madrid, Editorial Complutense.

GargureVICH, Juan (2005): Mario Vargas Llosa, reportero a los quince años, Lima, Pontificia Universidad Católica del Perú.

HILDEBRANDT, Martha (1949): «El español en Piura. Ensayo de dialectología peruana». Letras, Revista de la Universidad Nacional Mayor de San Marcos, 43, pp. 256-272.

ISAZA CALDERÓn, Baltasar (1986): Panameñismos, Ciudad de Panamá, Manfer.

ITURRI, Francisco (1798): Carta crítica sobre la historia de América del señor D. Juan Bautista Muñoz, Valencia, Imprenta de José de Orga.

IZQUIERDO Ríos, Francisco (1975): Pueblo y bosque, Lima, Villanueva.

LARRIVA, José Joaquín. (1864): «El fusilico del general Flores», en Colección de documentos literarios del Perú colectados y arreglados por el coronel Manuel de Odriozola, Lima, Tipografia de Aurelio Alfaro, II, pp. 129-148.

LÓPEZ AlBúJAR, Enrique (1966): De mi casona. Un poco de historia piurana a través de la biografia del autor, Lima, Juan Mejía Baca.

MARTín, José Luis (1974): La narrativa de Vargas Llosa. Acercamiento estilístico, Madrid, Gredos.

Membreño VÁsqueZ, Alberto de Jesús (1982): Hondureñismos. Vocabulario de los provincialismos de Honduras, Tegucigalpa, Editorial Guaymuras.

Oviedo, José Miguel (1970): Mario Vargas Llosa: la invención de una realidad, Barcelona, Seix Barral.

(1984): «Una discusión permanente», en César Hernández Moreno , coord., América Latina en su literatura, México, Siglo XXI, pp. 424-461.

Palacios, Víctor H. (2010): Piura en Mario Vargas Llosa y su obra, Piura, Editorial Pluma Libre.

PuIG, Estaban (1995): Breve diccionario folclórico piurano, Piura, Universidad de Piura.

RoldÁn, Julio (2000): Vargas Llosa, entre el mito y la realidad. Posibilidades y límites de un escritor latinoamericano comprometido, Marburg, Tectum Verlag.

SetTI, Ricardo A. (1989): Diálogo con Vargas Llosa, Buenos Aires, Intermundo.

Silva TUESTA, Max (2012): Mario Vargas Llosa. Interpretación de una vida, Lima, Editorial San Marcos.

Tola DE HABICH, Fernando y Patricia GRIEVE (1971): Los españoles y el boom. Cómo ven y qué piensan de los novelistas latinoamericanos, Caracas, Tiempo Nuevo.

Unamuno, Miguel de (1981): De Fuerteventura a París. Diario intimo de confinamiento y destierro en sonetos, Bilbao, El Sitio.

VARGAS LlosA, Mario (1966): La casa verde, Barcelona, Seix Barral.

- (1969): Conversación en la catedral, Barcelona, Seix Barral. (1971): Historia secreta de una novela, Barcelona, Tusquets. (1985): Semana de autor, Madrid, Ediciones de Cultura Hispánica. (2005): The Green House, New York, Harper Collins.

VARGAS UGARTE, Rubén (s. f.): Glosario de peruanismos, Lima, Librería e Imprenta Gil.

VelÁzQuez de la CAdenA, Mariano (1858): A Dictionary of the Spanish and English Languages, New York, Appleton and Co. 